\title{
DESIGN OF STRUCTURES FOR A ROAD ON EXTREMELY IRREGULAR GROUND
}

\author{
Riste Ristov $^{1}$ \\ Jovan Br. Papić ${ }^{2}$ \\ Zlatko Zafirovski ${ }^{3}$ \\ Slobodan Ognjenović ${ }^{4}$
}

UDK: $625.7(497.7)$

DOI: $10.14415 /$ konferencijaGFS2014.133

Summary: Gradsko-Prilep is one of the most frequent roads in R. Macedonia. Along the road there are several sections that pose serious obstacles for regular traffic flow in this central state road along east-west axis. Thus, the Public Enterprise for state road network has defined the Project Program for preparation of project documentation for its improvement. The planned section starts with deleveled connection with existing road and continues along the River Raec through canyons of Farishka and Drenovska rivers, ending with deleveled Drenovo interchange. The route ground is generally variable and extremely irregular. It can be classified as lowland to explicitly mountain terrain. The projected speed of $100 \mathrm{~km} / \mathrm{h}$ requires a wider horizontal and vertical centre line, demanding numerous supporting structures on the body of the road. This paper presents the approach and method of designing along the entire route.

Keywords: Road, Design, Improvement, Ground, Irregular

\section{INTRODUCTION}

Recently designed road A1e Gradsko-Prilep will be very frequent road as it will serve as a communication route between municipalities in Central and South-West Macedonia and Skopje. This road is also an appropriate East-West corridor in R. Macedonia. Regarding its frequency and direction, it is classified as a trunk road for vehicular circulation only, with speed of $100 \mathrm{~km} / \mathrm{h}$. Its length is about $53 \mathrm{~km}$.

The route road corridor is characterized with various topographic features. Most specific is the section from the River Raec to the road interchange Drenovo, in length of $9 \mathrm{~km}$, which varies from hill to mountain height. Distinctive areas are canyons of Fariska and Drenovska rivers, where the road mainly follows the bed of River Raec. The configuration of a ground in canyons, proximity of the river and the proposed speed

\footnotetext{
${ }^{1}$ BSc. C. E., Prostor AD, Mosa Pijade 2, Kumanovo, R. Macedonia, phone: +389 31475 515, riste.ristov@prostor.mk

${ }^{2}$ BSc. C. E., University "Ss. Cyril and Methodius", Faculty of Civil Engineering, Partizanski odredi 24,

Skopje, R. Macedonia, phone: +389 23116 066, papic@gf.ukim.edu.mk

${ }^{3}$ BSc. C. E., ditto, zafirovski@gf.ukim.edu.mk

${ }^{4}$ BSc. C. E., ditto, ognjenovic@gf.ukim.edu.mk
} 
require application and construction of larger structures as tunnels, bridges, retaining walls etc. Their specifics are briefly described below, while the commonly used structures are not discussed.

\section{ROAD SECTION}

The road route is designed as an expressway with width of $2 \times 3.5+2 \times 2.7=12.4 \mathrm{~m}$. It will be the phase 1 of a future motorway (phase 2), with overall width of $4 \times 3.75+2 \times 2.7+4.0=25.4 \mathrm{~m} \mathrm{[2]}$.

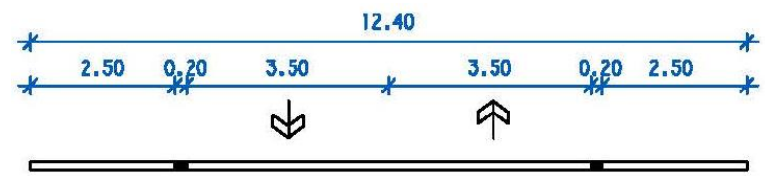

Figure 1. Geometrical cross-section of expressway

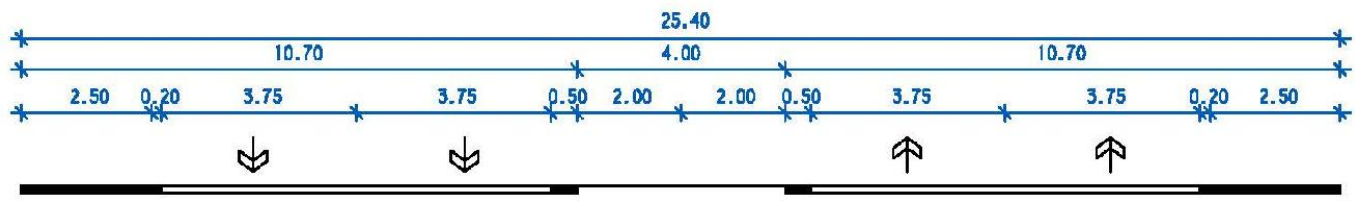

Figure 2. Geometrical cross-section of motorway

When determining the horizontal and vertical solution for the expressway, it was taken into account that it will become a motorway (by upgrading from one side), which can be performed in the part of the route with rather favourable conditions of the ground. However, due to various ground heights in the canyons of Fariska and Drenovska rivers, with significant alterations of incidence lines in transverse and longitudinal direction, this solution will not be applicable in a future period (when the road is supposed to become motorway). Designing of expressway with width of $12.4 \mathrm{~m}$ in such limitations would cause significant problems in the phase 2 , especially regarding the nearby structures. Thus, it was suggested to perform the motorway section at once, but since the clearance width of $25.4 \mathrm{~m}$ is too large, it was decided to reduce the section by excluding the emergency lane and reduction of the median strip width from 4.0 to $1.5 \mathrm{~m}$. Such $17 \mathrm{~m}$ wide section would extend to $\mathrm{km} 2+500.0$, while the median strip near the tunnels would be extended to $8.8 \mathrm{~m}$ to enable protective width between the openings.

\section{SITUATION AND LONGITUDINAL PROFILE}

For a section of the road elements of horizontal and vertical solution for design speed of $100 \mathrm{~km} / \mathrm{h}$ were applied. During the route location it was taken into account that the horizontal and vertical solutions are adapted to the basic design rules and conditions of the ground, even though the canyons of Drenovska and Fariska rivers are very hard to 
meet those principles. Additional obstacle while determining the final route of the expressway was the demand that the newly designed route and the route of existing regional road P-106 shall not intersect, in order to maintain the existing road as a parallel. These intersection points also affect the determination of a grade line.

Poor ground configuration, nearby location of the Raec river bed, and the location of P106 do not allow opportunity for greater application of other values of elements of horizontal solution in order to enlarge or reduce the directions to their allowable limits. Namely, if other elements of horizontal solution are applied - i.e., relocation of points to meet requirement - the centre road line would be radically changed, thus demanding new structures to be built in some places, enlargement of planned structures and extended earthworks [1].

\section{APPLIED STRUCTURES ALONG THE ROAD ROUTE}

Such limiting elements require larger number of structures. At some parts of the route, especially in canyons where the clearance is wider, guardrails of the New Jersey type are installed in order to separate roadway lanes.

Walls of $1.5 \mathrm{~m}$ are placed near the gutter to protect the roadway from rockfalls in a case of cuts higher than $5 \mathrm{~m}$.

\subsection{Securing of slopes}

The height of embankments is one of the principles during the determination of the grade line of the road. Namely, attention was paid for their height not to extend $8-10 \mathrm{~m}$; in such case bridge structures were applied.

The projected embankment slope inclination at the most part of the route is $1: 2$, mostly because of the visual impression. At some parts of the road route, especially where the expressway approaches to existent road P-106, slopes with greater inclination of 1:1.5 are planned in order to avoid additional structures. Decrease of the slope inclination of embankments from $1: 2$ to $1: 1.5$ is in line with the inclinations recommended by the Geotechnical Elaborate.

"Complex" ground configuration requires application of higher slopes for cuts and notches extending to $30(35) \mathrm{m}$ at some locations. Depending on geomechanical properties of the ground, different cut slopes were applied (from 2:1 to 5:1). According to the Elaborate, benches are not provided for embankment slopes of 2:1, while benches of 8-10 $\mathrm{m}$ height and $3 \mathrm{~m}$ width are provided for steep slopes.

Basing on conducted analysis of geological and geomechanical properties of the environment, structural and texture properties of rocks, crack system and inclination of the layers, it is estimated that possible measures for stabilization and protection of slopes would include application of various independent or combined methods for securing the slopes at a same surface. Following types of stabilization and protection measures that will be applied at particular slopes from sections (cut and notch) are planned:

Type 1 - local scratching of unstable blocks;

Type 2 - placing of single protective galvanized net, with local non-systematic anchoring with $\mathrm{SN}$ anchors; 
International conference

Contemporary achievements in civil engineering 24. - 25. April 2014. Subotica, SERBIA

Type 3 - systematic anchoring of fractured blocks and protection of slopes with passive SN anchors;

Type 4 - systematic protection of slopes with passive SN anchors and placing of reinforcement net;

Type 5 - anchoring of potentially unstable zones in combination with sprayed concrete, reinforcement net and SN anchors [3].

\subsection{Bridge and half-bridge structures}

Starting from $\mathrm{km} 0+706.06$ to $\mathrm{km} 1+311.26$, namely in the area of Fariska River canyon, there is a need to build several bridge and half-bridge structures. Because of the unique ground conditions, all of the structures mentioned above are attached one to another representing a single complex, so they are analyzed at once [4].

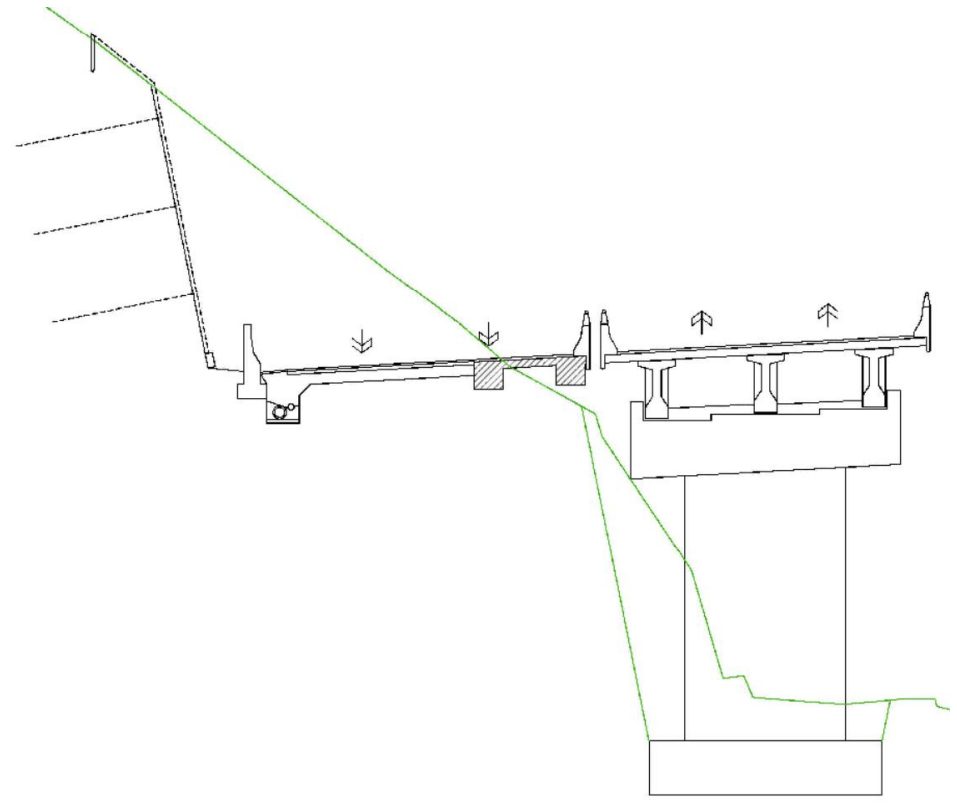

Figure 3. Cross-section of a half-bridge structure

The structure on the upper structure at bridges is comprised of 3 prefabricated main reinforced girders and monolith transverse girders and reinforced slab. Ending piers (abutments) are either monolith reinforced concrete walls with constant section, or comprised of three individual piers connected to the upper part with supporting beam (depending on the height and ground conditions). Wing walls are performed as reinforced concrete walls with constant thickness and strip foundation.

\subsection{Tunnel}

The tunnel is planned with two openings, since this part of the road has the wider clearance. According to the construction of tunnel openings, it is necessary to provide at least $8 \mathrm{~m}$ spacing between them [5]. 
Међународна конференција

Савремена достигнућа у грађевинарству 24.-25. април 2014. Суботица, СРБИЈА

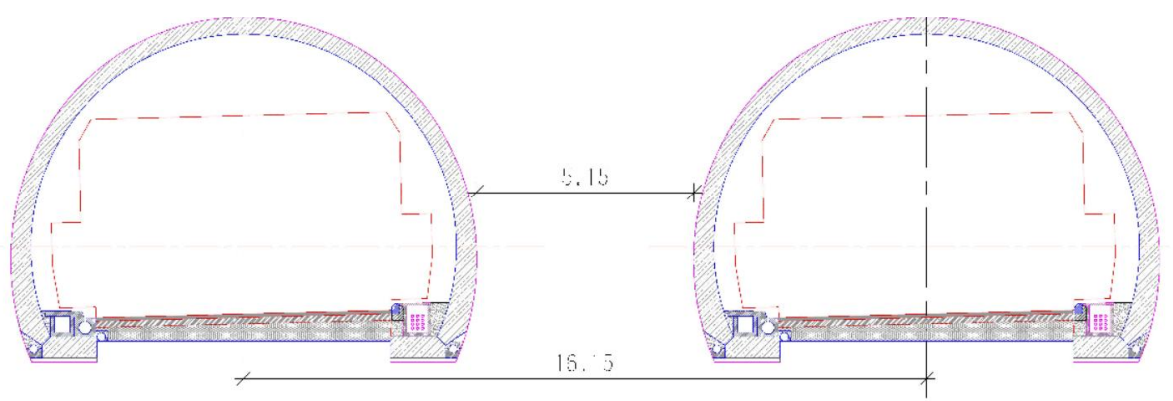

Figure 4.Cross-section of tunnel tubes

\subsection{Gallery}

The expressway route cuts across the ground forming slope higher than $45 \mathrm{~m}$. A study was conducted concerning the risk assessment for that slope including analysis of a free fall of a stone with weight of $0.1 \mathrm{~kg}$. The study elaborates several scenarios for protection from a rockfall [6].
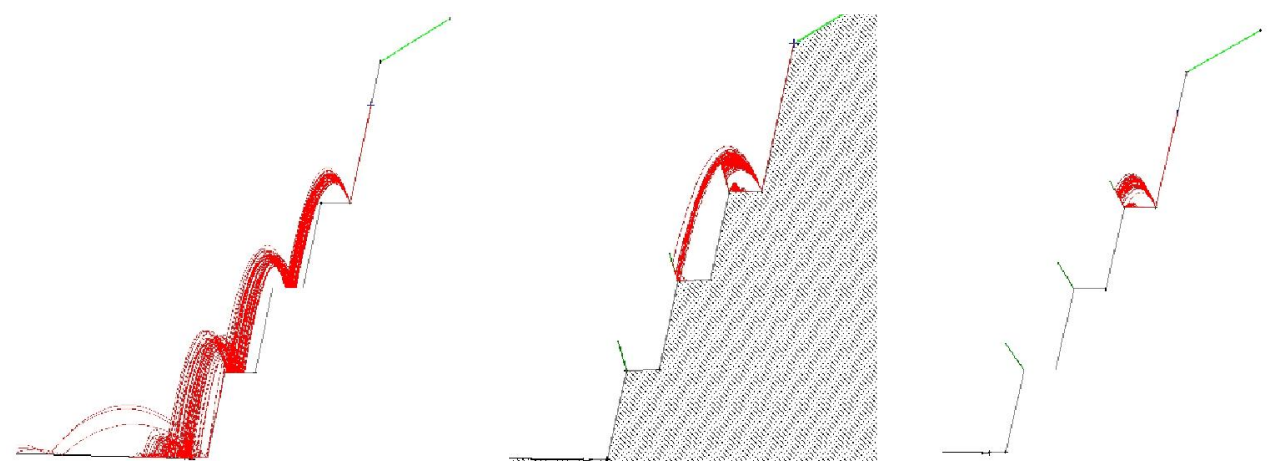

Figure 5. Slope analysis with Rock Fall software

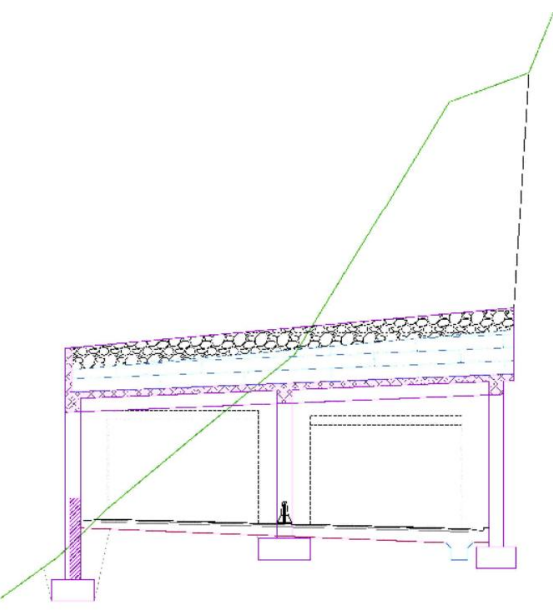

Figure 6. Gallery cross-section 


\section{CONCLUSIONS}

During the route location process, several approaches for finding the most appropriate position and shape of the road were conducted, i.e., the spatial line comprised of separate and mutually connected and completely defined elements was determined and defined. The one with the smallest costs of construction, maintenance and exploitation was adopted as the most favourable route. Adaptation of the route to the ground configuration in situation and longitudinal section decreases the construction costs. Regarding the exploitation, larger radius and smaller longitudinal inclinations are more favourable, although the construction costs are larger. When selecting the design elements, attention was paid to the significance of the road, traffic load, structure of vehicles and ground configuration.

Since this trunk road is planned for a larger traffic density, inclinations of the grade line have to be smaller, because the bigger inclinations would lead to a slower traffic flow. However, decrease of inclinations of the grade line for unfavourable terrains would extend the length of a route and increase the size of the structures. Planned structures are analyzed for their cost-effectiveness, after which their adequacy was confirmed.

\section{REFERENCES}

[1] Base design for route Prilep-Gradsko, section r. Raec - DI Drenovo, Civil Engineering part (route), Book No.3, 2013.

[2] Rulebook for technical elements for building and re-construction of public roads and structures at roads, Ministry of transport and communications of R. Macedonia, 2009.

[3] Base design for route Prilep-Gradsko, section r. Raec - DI Drenovo, Geotechnical Elaborate, Book No.2, 2013.

[4] Base design for route Prilep-Gradsko, section r. Raec - DI Drenovo, RC bridge structures, Book No.9, 2013.

[5] Base design for route Prilep-Gradsko, section r. Raec - DI Drenovo, Tunnel at km 0+630.00, Book No.10, 2013.

[6] Base design for route Prilep-Gradsko, section r. Raec - DI Drenovo, RC gallery, Book No.11, 2013. 